\title{
DESIGN VISUALISASI LOGO SEBAGAI IDENTITY PROGRAMS DI DIVISI RAHARJA ENRICHMENT CENTRE
}

\author{
Anita B. Wandanaya ${ }^{1}$ \\ Dewi Immaniar ${ }^{2}$ \\ Maryana Astuti’3 \\ e-mail:anita@raharja.info; dewi.immaniar@raharja.info; \\ maryana.astuti@raharja.info \\ Diterima : 10 Februari 2014 / Disetujui : 15 April 2014
}

\begin{abstract}
One of the important things in a visual media institution is a public institution of the logo identity. Identity logo itself has a meaning as an identity that represents the image of an institution. Division Raharja Enrichment Centre was commissioned to complete the implementation of Tri Dharma on Higher Education Prog which concentrates on research and service to society. Enrichment programs Prog Centre issued has not had a logo identity. Without the identity logo to the program have not been able to realize the identity of ownership to the public. For that, it takes a logo identity for each of the programs Raharja Enrichment Centre which can be interesting and can be implemented as the identity of the visual. The one of methode in this study used Design Analys Method with applications supporting Adobe Illustrator CS5 applications such as processor design objects vector image, while Adobe Photoshop CS5 application used to process bitmap images and Design Concept Plan contains the media. With the logo identity of each of these programs, the public will be easily understood by looking at a consistent look and is easily recognizable because it has special characteristics in each of its programs. From the design of the logo identity is expected for subsequent years may give a different look and appeal in introducing programs of the Raharja Enrichment Centre.
\end{abstract}

Keywords: Design, Identity Logo, Design Analys Method

1. Dosen Jurusan Teknologi Informasi, STMIK Raharja

Jl. Jend Sudirman No. 40 Modern Cikokol-Tangerang Telp. 5529692

2. Dosen Jurusan Teknologi Informasi, STMIK Raharja

Jl. Jend Sudirman No. 40 Modern Cikokol-Tangerang Telp. 5529692

3. Mahasiswa Jurusan Teknologi Informasi, STMIK Raharja

Jl. Jend Sudirman No. 40 Modern Cikokol-Tangerang Telp. 5529692 


\section{ABSTRAKSI}

Salah satu hal penting dalam suatu media visual lembaga institusi terhadap publik adalah sebuah identitas logo. Identitas logo sendiri memiliki arti sebagai identitas yang mewakili image sebuah lembaga institusi. Raharja Enrichment Centre adalah Divisi yang ditugaskan untuk melengkapi pelaksanaan Tri Dharma pada Perguruan Tinggi Raharja yang berkonsentrasi pada penelitian dan pengabdian untuk masyarakat. Program-program Raharja Enrichment Centre yang dikeluarkan selama ini belum memiliki sebuah identitas logo. Tanpa adanya identitas logo pada program-programnya belum bisa mewujudkan identitas kepemilikan kepada publik. Untuk itu, dibutuhkan identitas logo untuk setiap program-program Raharja Enrichment Centre yang dapat menarik dan dapat diimplementasikan sebagai identitas visualnya. Salah satu Methode yang digunakan dalam penelitian ini adalah menggunakan Metode Analisa Perancangan dengan dipergunakan aplikasiaplikasi penunjang diantaranya aplikasi Adobe Illustrator CS5 sebagai pengolah rancangan objek-objek gambar vector, sertaaplikasi Adobe Photoshop CS5 dipergunakan untuk mengolah gambar bitmap dan Konsep Desain berisi mengenai Perencanaan media. Dengan adanya identitas logo dari setiap program-program tersebut, publik akan mudah memahaminya dengan melihat sebuah tampilan yang konsisten dan mudah dikenali karena memiliki karakteristik khusus pada setiap program-programnya. Dari hasil rancangan identitas logo tersebut diharapkan untuk tahun-tahun berikutnya dapat memberikan suatu tampilan yang berbeda dan menarik dalam memperkenalkan program-program Raharja Enrichment Centre tersebut.

Kata Kunci : Perancangan, Identitas Logo, Methode Analisa Perancangan

\section{PENDAHULUAN}

Identitas digunakan untuk memperkenalkan sebuah perusahaan atau lembaga institusi kepada publik. Identitas juga dapat digunakan untuk memperkenalkan program ataupun produk kepada publik sebagai perwakilan dari image perusahaan. Logo sebagai sebuah lambang yang memberi suatu identitas, informasi, dan persuasi. Oleh karena itu, Logo harus memiliki ciri khusus sehingga dapat membangun image atau citra agar lebih mudah dikenal, baik dalam lingkungan internal maupun eksternal dari lembaga insitusi tersebut.

REC (Raharja Enrichment Centre) adalah Divisi yang ditugaskan untuk melengkapi pelaksanaan Tri Dharma pada Perguruan Tinggi Raharja yang berkonsentrasi pada penelitian dan pengabdian untuk masyarakat. Pada tanggal 11 Desember 2003 telah berdirinya Raharja Enrichment Centre (REC). 
Raharja Enrichment Centre (REC) dari tahun ke tahun mengeluarkan programprogram terbaru untuk memudahkan dalam berkomunikasi dengan dosen maupun antar pribadi raharja. Berikut adalah tabel informasi program - program yang ada di Raharja Enrichment Centre:

Tabel 1. Tabel Program REC

\begin{tabular}{|c|c|l|}
\hline No & $\begin{array}{c}\text { Jenis Logo yang } \\
\text { dibutuhkan }\end{array}$ & \multicolumn{1}{|c|}{ Deskripsi Logo } \\
\hline 1. & Logo iMe & $\begin{array}{l}\text { Berupa logo yang mencerminkan sebuah website iLearming yang } \\
\text { dikemas secara khusus untuk kegiatan pembelajaran secara online. }\end{array}$ \\
\hline 2. & Logo iDu & $\begin{array}{l}\text { Berupa logo yang mencerminkan sebuah sistem pembelajaran yang } \\
\text { dikembangkan oleh Perguruan Tinggi Raharja untuk memudahkan } \\
\text { civitas kampus dan mahasiswa dalam menjalankan perkuliahan. iDu bisa } \\
\text { diakses dimanapun dan kapanpun. }\end{array}$ \\
\hline 3. & Logo Rinfo & $\begin{array}{l}\text { Berupa logo yang mencerminkan sebuah prasarana komunikasi yang } \\
\text { digunakan seluruh pribadi raharja. }\end{array}$ \\
\hline 4. & Logo iLearning & $\begin{array}{l}\text { Berupa logo yang mencerminkan sebuah sistem pembelajaran dalam } \\
\text { upaya memberikan pelayanan prima kepada seluruh mahasiswa/i dalam } \\
\text { bentuk service excellence sebagai kampus unggulan. }\end{array}$ \\
\hline 5. & Logo iSur & $\begin{array}{l}\text { Berupa logo yang mencerminkan sebuah sistem survey yang terintergrasi } \\
\text { secara online di Perguruan Tinggi Rahaja untuk memberikan informasi } \\
\text { yang efektif, efisien dan akurat. }\end{array}$ \\
\hline 6. & Logo iRan & $\begin{array}{l}\text { Berupa logo yang mencerminkan sebuah sistem pelayanan informasi } \\
\text { seputar Perguruan Tinggi Raharja yang dapat diakses secara online dan } \\
\text { memberikan pelayanan berupa pertanyaan dan jawaban secara akurat. }\end{array}$ \\
\hline 7. & Logo iDuHELP & $\begin{array}{l}\text { Berupa logo untuk menunjang kegiatan para mahasiswa/i Perguruan } \\
\text { Tinggi Raharja dalam melakukan pengabdian dikampus. Serta } \\
\text { mempunyai tujuan membantu calon mahasiswa maupun pribadi raharja } \\
\text { dalam mengakses informasi mengenai bagian marketing atau akademik. }\end{array}$ \\
\hline 8. & Logo iRME & $\begin{array}{l}\text { Berupa logo untuk mengakomodir dan memfasilitasi pribadi raharja } \\
\text { dalam upaya pengumpulan portofolio pribadi, orientasi surat lamaran } \\
\text { kerja atau CV. }\end{array}$ \\
\hline 9. & Logo Rooster & $\begin{array}{l}\text { Berupa logo untuk sistem pelayanan yang melayani secara online dengan } \\
\text { menggunakan sistem e-ticket atau ticketing online pada Perguruan } \\
\text { Tinggi Raharja. }\end{array}$ \\
\hline
\end{tabular}

Sumber : Raharja Enrichment Centre (REC)

Untuk memperkenalkan program-programnya diatas Raharja Enrichment Centre (REC) saat ini sangat membutuhkan media logo yang dapat menggambarkan karakteristik dari setiap program-programnya agar dapat menarik perhatian Dosen dan pribadi raharja.

Berdasarkan masalah diatas diuraikan disini bagaimana membuat sebuah rancangan Identitas Logo yang menarik dan mewakili citra atau image Raharja Vol.8 No.1 - September 2014 
Enrichment Centre (REC) sehingga menghasilkam sebuah tampilan logo yang menarik, warna yang harmonis dan font yang kreatif serta bagaimana Identitas Logo ini di implementasikan sebagai identitas visual dalam menampilkan program-program Raharja Enrichment Centre (REC) dan dapat memberikan karakteristik khusus pada setiap program-program Raharja Enrichment Centre tersebut agar terlihat berbeda pada setiap programnya. Adapun program-program yang membutuhkan logo adalah iMe, iDu, eCo, iLearning, iSur, iRan, iDuHELP, iRME dan Rooster. Perancangan Identitas logo program Raharja Enrichment Centre (REC) meliputi warna, bentuk huruf dan rancangan visual beserta filosofinya.

Tujuan dari penelitian ini adalah dapat menciptakan sebuah rancangan dari kesederhanaan tampilan visual yang memperkenalkan identitas logo dari setiap program-program Raharja Enrichment Centre sehingga memudahkan dalam penyampaian pesannya kepada publik. Nuansa yang disampaikan dari rancangan identitas logo ini modern dan terkesan unik. Dari setiap rancangan identitas logo segi visual ditampilkan melalui pendekatan dan rasa ingin tahu publik dengan melihat logo tersebut menjadi tertarik. Karena tampilan visual dengan bentuk gambar yang menarik dan kalimat yang membujuk untuk mempengaruhi tingkat emosional seseorang.

\section{KAJIAN LITERATURE}

1. Banyak penelitian yang sebelumnya dilakukan mengenai perancangan logo. Penelitian ini merujuk kepada beberapa Pada penelitian sebelumnya yaitu Penelitian yang dilakukan oleh Suci Riatma Wardani dari Perguruan Tinggi Raharja pada tahun 2011 dengan judul "Redesign Corporate Identity dan Perancangan Graphic Standar Manual pada PT. Dunia Bangunan”. Penelitian ini membahas tentang merancang ulang sebuah Corporate Identity dan menciptakan rancangan media menggunakan acuan Graphic Standar Manual melalui gambar ilustrasi media yang digunakan agar lebih menarik dan dinamis. Diharapkan dengan Graphic Standar Manual ini dapat memberikan suatu penjelasan bagi setiap pihak institusi atau perusahaan dalam mensosialisasikan sebuah identitas institusi atau perusahaan.

2. Penelitian kedua selanjutnya dilakukan oleh Chyki Febrina dan R. Eka Rizkiantono dari Institut Teknologi Sepuluh Nopember (ITS) pada tahun 2013 dengan judul "Perancangan Identitas Visual Kampoeng Sepatu Sandal Krian 
sebagai Kampoeng Wisata Industri di Sidoarjo”. Penelitian ini menjelaskan tentang sentra industri pengrajin sepatu Krian menjadi salah satu desa wisata industri yang ada di Sidoarjo, sehingga untuk mendukung hal tersebut, diperlukan identitas visual yang mengkomunikasikan Kampoeng Sepatu Sandal Krian sebagai kampoeng wisata industri. Metode riset yang digunakan adalah dengan melakukan penggalian data yang berkaitan dengan Kampoeng Sepatu Sandal krian yang didapat dari stake holder maupun pengrajin. Hasil dari kegiatan tersebut dikaji melalui studi pustaka lalu dikomparasikan dengan kompetitor dan komparator untuk menemukan analisa SWOT dari Kampoeng Sepatu Sandal krian. Analisa tersebut digunakan dalam pembuatan identitas visual Kampoeng Sepatu Sandal krian. Pada proses perancangan identitas visual ini akan dibuat sebuah logo atau identitas mewakili visi dan misi kampoeng tersebut dengan konsep kreatif dan dinamis, Selain itu akan dibuat pula sebuah sistem grafis yang mendukung serta pengaplikasiannya pada media keperluan kampoeng, seperti stationery set, media marketing, merchandising, dan Envronmental Graphic Design.

3. Dan Penelitian ketiga dan yang terakhir dilakukan oleh Dyas Tangguh Ikranegara dan R. Eka Rizkiantono dari Institut Teknologi Sepuluh Nopember (ITS) pada tahun 2013 dengan judul "Perancangan Identitas Visual Museum 10 Nopember 1945 Surabaya”. Penelitian ini menjelaskan tentang merancang sebuah identitas visual museum 10 Nopember 1945 Surabaya maka diperlukan metode dalam memperoleh konsep dan hasil desainnya, antara lain yaitu melakukan studi tentang ruang lingkup Museum 10 Nopember baik dari segi perusahaan dan pengembangannya, visi dan misi, keunggulan dan serta nilainilai yang terkandung dalam museum 10 Nopember, melalui wawancara mendalam dan juga literatur buku sejarah, selain itu untuk mendapatkan hasil estetika yang baik maka diperlukan juga studi tentang kaidah-kaidah desain yang didapatkan melalui literatur buku, studi eksisting dan studi komparator. Setelah melalui proses penelitian dengan metode yang diterapkan, maka konsep desain yang diperoleh yaitu "History of Fighting Spirit”, pengaplikasian bentuk dalam desain adalah bentukan yang mewakili sifat semangat, optimisme, patriotik, dan keberanian, sebagaimana Museum 10 Nopember 1945 Surabaya merupakan tempat wisata yang beredukasi dan juga menyuguhkan sebuah warisan sejarah dan nilai patriotisme. Identitas visual museum 10 Nopember 1945 Surabaya ini diharapkan dapat mencerminkan visi, misi, pengembangan museum 10 Nopember, disamping itu juga diharapkan mampu mencerminkan diferensiasi budaya kepahlawanan dan keunikannya. 


\section{LANDASAN TEORI}

Menurut Iwan Binanto (2010 : 260-261) Perancangan adalah tahap pembuatan spesifikasi mengenai arsitektur program, gaya, tampilan, dan kebutuhan material atau bahan untuk program. Tahap ini biasanya menggunakan storyboard untuk menggambarkan deskripsi tiap scene lain dan bagan alir (flowchart) untuk menggambarkan aliran dari satu scene ke scene lain. Proses Perancangan Secara Umum menurut Hendi Hendratman (2010 : 09-12) terdiri dari persiapan data, Idea, Konsep, Media, Visualisasi dan Produksi.

Selain Teori mengenai Perancangan, terdapat juga pengertian desain yang perlu diketahui. Menurut Rakhmat Supriyono (2010 : 136) Desain merupakan art direction, yaitu penampilan visual secara menyeluruh dari iklan. Hasil kerja sama antara art direction dan copywriter (berupa konsep verbal dan visual) dipadukan secara sinergis ke dalam desain melalui proses standar, yaitu membuat sketsa-sketsa kasar, menentukan alternatif desain, hingga final artwork (FAW).

Pengertian lebih jelas mengenai Logo dapat disampaikan sebagai berikut. Menurut Ferri Caniago (2012 : 3) Logo merupakan suatu bentuk gambar atau sekedar sketsa dengan arti tertentu dan memiliki suatu arti dari perusahaan, daerah, perkumpulan, produk, negara dan hal-hal lainnya yang dianggap membutuhkan hal yang singkat dan mudah diingat sebagai pengganti dari nama sebenarnya.

\section{METODE PENELITIAN}

Didalam perolehan data lebih akurat dipenelitian ini, terdapat beberapa penerapan metode, yaitu : (1). Metode Analisa Permasalahan. Metode ini merupakan suatu metode yang digunakan untuk menentukan topik permasalahan penelitian, dalam hal ini dilakukan dengan bentuk interview yang menanyakan tentang permasalahanpermasalahan yang terdapat pada lembaga instansi yang terkait dengan penggunaan Identitas logo terhadap reputasi Perguruan Tinggi Raharja khususnya bagian Divisi Raharja Enrichment Centre (REC); (2). Metode Pengumpulan Data yaitu cara untuk mendapatkan data dengan jalan pengamatan secara langsung ke lokasi (Observasi), Interview ataupun dari kajian pustaka; (3).Analisa Data berupa pengolahan data atau informasi yang diangkat dari hasil perancangan dan penelitian terhadap profile Raharja Enrichment Centre (REC) yang akan dianalisa dan diolah menggunakan software atau aplikasi program yang mendukung dalam proses perancangan; 
(4).Metode Analisa Perancangan, dalam produksi Perancangan Identitas logo Sebagai Penunjang Informasi Divisi Raharja Enrichment Centre Pada Perguruan Tinggi Raharja dipergunakan aplikasi-aplikasi penunjang diantaranya aplikasi Adobe Illustrator CS5 sebagai pengolah rancangan objek-objek gambar vector, sedangkan aplikasi Adobe Photoshop CS5 dipergunakan untuk mengolah gambar bitmap; (5). Konsep Desain berisi mengenai Perencanaan media yang terdiri dari Tujuan Media, Strategi Media dan Program Media. Perencanaan Pesan terdiri dari Tujuan Pesan dan Strategi Pesan. Perencanaan Visual terdiri dari Tujuan Visual, Strategi Visual, Penulisan Naskah, Pengarahan Visual dan Proses Desain yang terdiri dari tiga tahap proses yaitu layout kasar, layout kompherensif dan layout final art work.

\section{PEMBAHASAN (KONSEP DESAIN)}

\section{Perencanaan Media}

Media penunjang identitas logo yang akan digunakan untuk program-program pada Raharja Enrichment Centre direncanakan berupa : Media Booklet. Sedangkan media yang digunakan untuk memperkenalkan program-program di Raharja Enrichment Centre berupa : Logo iMe, Logo iDu, Logo eCo, Logo iLearning, Logo iSur, Logo iRan, Logo iDuHELP, Logo iRME dan Logo Rooster.

\section{Perencanaan Pesan (Konsep Kreatif)}

Konsep perencanaan pesan atau kreatif yang ingin dituangkan ke dalam media adalah sebuah ide kreatif yang didapat berdasarkan dari data-data atau obyek yang diperoleh di Raharja Enrichment Centre, kemudian diolah menjadi sebuah rancangan logo-logo yang menarik yang dilakukan pada setiap halaman sesuai dengan kebutuhan. Perencanaan Pesan (Konsep Kreatif) dibagi menjadi Tujuan Kreatif dan Strategi Kreatif. Tujuan kreatif ini adalah untuk menarik perhatian lingkungan internal maupun eksternal Perguruan Tinggi Raharja dalam memperkenalkan programprogram yang telah dibuat oleh Raharja Enrichment Centre dengan melihat sebuah tampilan logo yang menarik, warna yang harmonis dan font yang kreatif. Strategi Kreatif mengenai isi pesan dan bentuk pesan. Isi pesan dalam perancangan logo sudah mewakili setiap program-program yang ada di Raharja Enrichment Centre seperti berisi kalimat yang menjelaskan filosofi dan program-program itu sendiri. Sedangkan bentuk pesan membahas sebuah identitas logo yang mudah dikenal oleh lingkungan eksternal maupun internal perguruan tinggi raharja. yaitu terdiri dari gambar, 
warna dan tulisan. Dengan adanya identitas logo ini, dapat memberikan karakteristik khusus pada setiap program-program Raharja Enrichment Centre agar terlihat berbeda pada setiap programnya.

\section{Perencanaan Visual}

Media booklet, akan ditampilkan kalimat yang digunakan sebagai headline IDENTITAS LOGO PROGRAM-PROGRAM RAHARJA ENRICHMENT CENTRE yang ditulis dengan huruf besar dengan jenis huruf besar dan bold yang mempunyai karakter kuat. Perencanaan Visual agar lebih fokus maka diterapkan Tujuan Visual dan Strategi Visual. Tujuan Visual menjelaskan esederhanaan tampilan visual pada setiap rancangan bertujuan untuk memperkenalkan sebuah identitas logo dari setiap program-program Raharja Enrichment Centre sehingga memudahkan dalam penyampaian pesannya kepada publik. Nuansa yang ingin disampaikan peneliti pada setiap rancangan identitas logo ini yaitu modern dan terkesan unik.Strategi Visual, pada setiap rancangan identitas logo ini ditampilkan dengan gambar yang modern dan terkesan artistik serta unik. Adapun strategi visual yang ingin ditampilkan yaitu melalui pendekatan dan rasa ingin tahu publik dengan melihat logo tersebut menjadi tertarik. Karena tampilan visual dengan bentuk gambar yang menarik dan kalimat yang membujuk untuk mempengaruhi tingkat emosional seseorang.

\section{Penulisan Naskah}

Pada rancangan identitas logo program-program Raharja Enrichment Centre, terdapat unsur-unsur komunikasi grafis seperti teks (tulisan). Teks (tulisan) sebagai headline, subheadline bodycopy ataupun closing yang diperlukan dalam perancangan agar mudah penyampaian pesan mudah dimengerti dan tepat sasaran, teks digunakan sebagai judul (headline), sub judul, naskah (bodycopy), logo (logotype) dan kata penutup (closing word). Berikut adalah penjelasan dari masing-masing bagian teks (tulisan). (1). Judul (headline) adalah bagian terpenting dari teks yang menarik perhatian dan merupakan hal yang pertama kali dibaca. Judul akan mengarahkan pembaca untuk lebih jauh mengetahui tentang isi dari sebuah pesan atau informasi yang ada di dalamnya. Khususnya pada media booklet, disampaikan filosofi logo dari setiap program-program Raharja Enrichment Centre dengan kalimat yang singkat, pendek dan jelas tapi tetap menarik sesuai dengan tujuan yang diinginkan; (2). Naskah (body copy) merupakan kalimat yang menerangkan lebih rinci tentang isi pesan yang ingin disampaikan, berfungsi untuk mengarahkan pembaca dalam mengambil sikap berpikir dan bertindak lanjut. Hal tersebut diterapkan pada media-media yang 
tingkat pemahaman waktunya relatif lama. Secara kreatif bentuk naskah atau body copy dapat dikombinasikan dengan visual yang disesuaikan dengan apa yang ingin disampaikan. Dalam logo ini, naskah yang ditampilkan berisi kalimat filosofi-filosofi yang sesuai dengan program-program Raharja Enrichment Centre dan kalimat-kalimat yang menarik dan mendidik; (3). Slogan adalah Moto atau frasa yang dipakai pada konteks politik, komersial dan lainnya. Sebagai ekspresi sebuah ide atau tujuan yang mudah diingat. Seperti pada program iLearning yang mempunyai sebuah tujuan untuk membuat mahasiswa menjadi lebih aktraktif dan semangat belajar yang didukung dengan teknologi iPad.

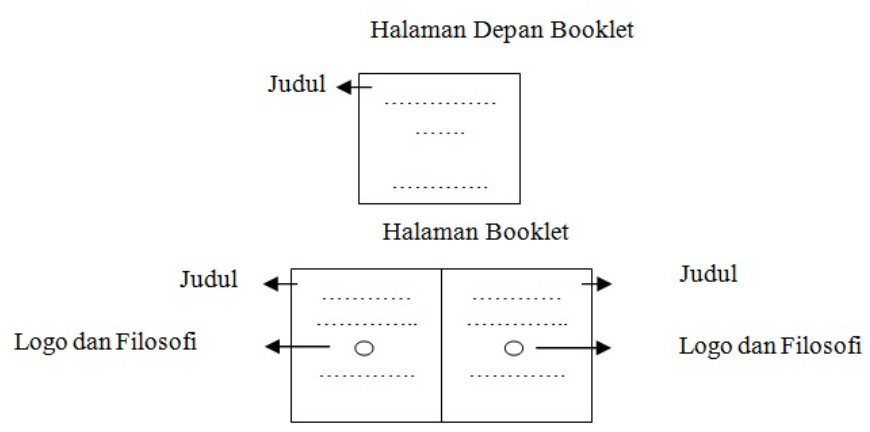

Gambar 1.Body Copy Booklet Program REC

\section{Pengarahan Visualisasi (Art Directing)}

Rancangan media Identitas Logo pada program-program Raharja Enrichment Centre agar memudahkan dalam memperkenalkan program-program tersebut secara visual kepada lingkungan internal maupun eksternal Perguruan Tinggi Raharja. Rancangan untuk logo tersebut menggunakan warna Hijau, Biru dan Merah serta warna lain sesuai dengan warna yang ada pada Perguruan Tinggi Raharja. Jenis huruf yang dipakai dalam perancangan ini diantaranya : Kartika Bold, Baby Universe, Arial Rounded MT Bold, New Athletic, Bahaus 93, Berlin Sans FB Bold, Myriad, Carbon Block.

\section{Proses Desain (Designing)}

Proses rancangan desain media booklet pada program-program Raharja Enrichment Centre dibuat dengan proses bertahap, yaitu : (1). Layout Kasar, (2). 
Layout Kompherensif, (3). Final Art Work. Dibawah ini adalah tahapan-tahapan proses rancangan drsain media booklet, yaitu :

\section{Layout Kasar}

Layout Kasar adalah penerapan elemen-elemen desain media yang nantinya akan dipergunakan dalam perancangan media komunikasi visual yang disertai acuan standarisasi pada desain yang akan dibuat, umumnya dibuat dengan tampilan hitam putih, dibuat dengan coretan atau sketsa dengan menggunakan pensil gambar. Layout kasar diperlukan, sebagai panduan pada saat proses desain dengan menggunakan aplikasi komputer. Berikut adalah gambar layout kasar proses perancangan logo program-program Raharja Enrichment Centre pada Perguruan Tinggi Raharja antara lain.
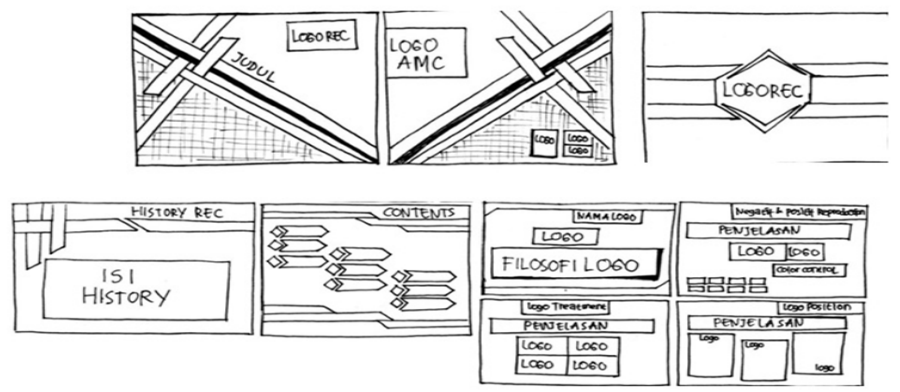

Gambar 2.Layout Kasar Booklet

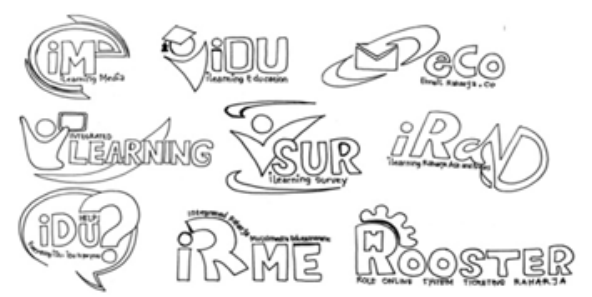

Gambar 3. Layout Kasar Identity Programs Di Divisi Raharja Enrichment Centre

\section{Layout Kompherensif}

Layout Kompherensif adalah proses desain yang sudah memasuki tahap komputerisasi dan pewarnaan, namun tahap ini belum selesai seluruhnya, karena 
masih harus mengalami proses revisi. Berikut adalah Layout Komprehensif Booklet Corporate identity program-program REC.

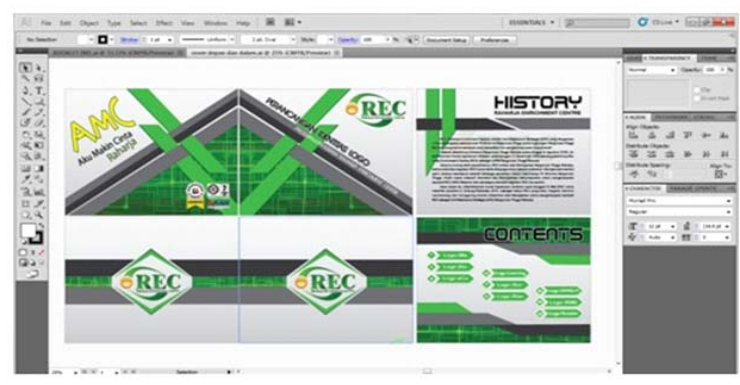

Gambar 4. Layout Kompherensif Cover dan Backcover Booklet.

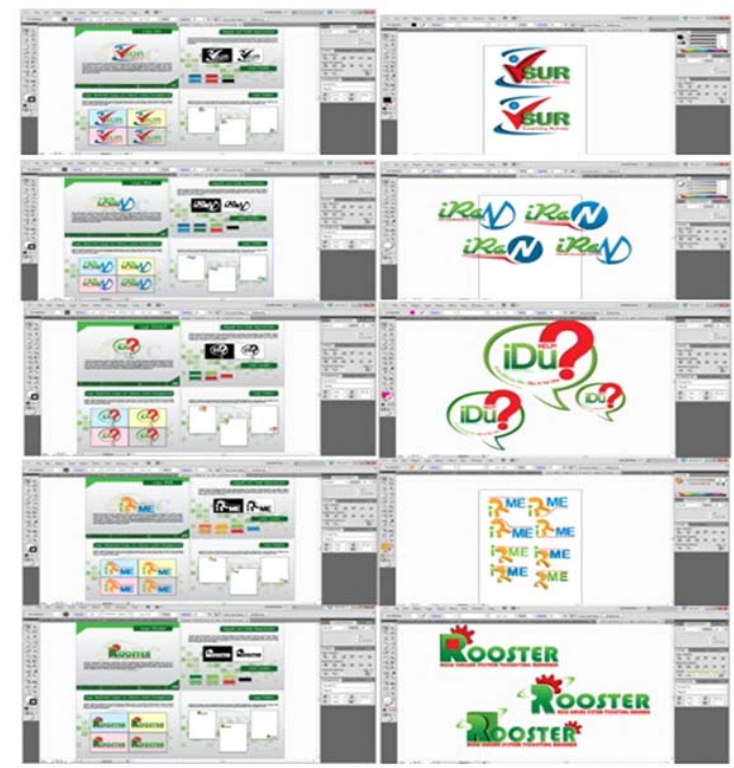

Gambar 5. Layout Kompherensif Booblet Logo Program-program di REC

\section{Final Artwork}

Hasil akhir dari layout komprehensif yang telah diperbaiki, dimana tahap ini merupakan hasil akhir atau finishing, yang kemudian dapat digunakan untuk acuan 
saat proses produksi. Berikut tahapan proses terakhir dari Perancangan Identitas Logo Program-Program Raharja Enrichment Centre antara lain Final Artwork Layout Booklet dan Final Artwork dari Logo Program-program REC.

Final Artwork :

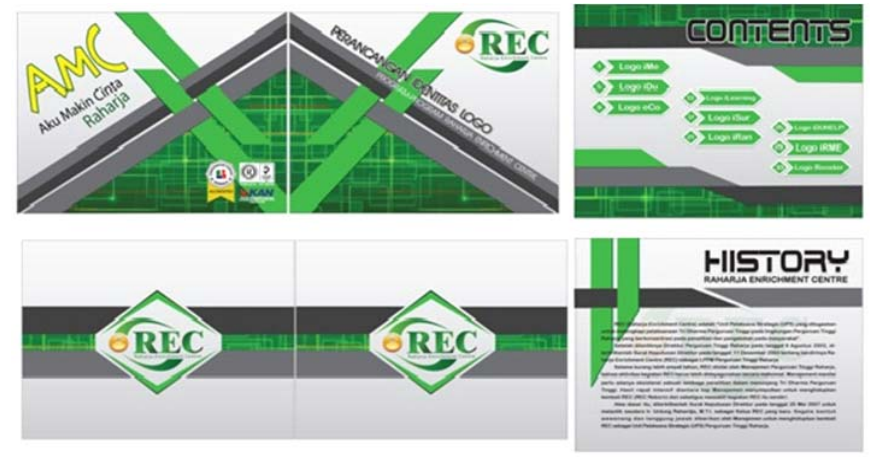

Gambar 6. Final Artwork Layout Booklet

Gambar 6 diatas menggambarkan hasil akhir yang telah finis berupa booklet untuk rangkupan logo dari program-program REC. Booklet diserahkan untuk pegangan perusahaan atau divisi sebagai acuan dalam placing logo untuk ke setiap media seperti penempatan logo untuk stationary ataupun media promosi lainnya.

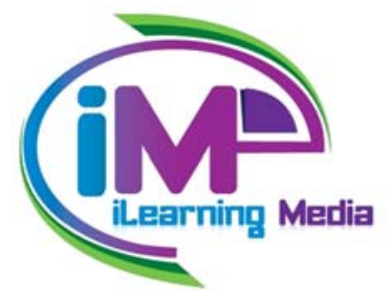

Gambar 7. Final Artwork Logo ime

iMe merupakan sebuah website yang dikemas secara khusus untuk kegiatan publisitas. Filosofi logo ini mengambil warna gradasi antara biru dan ungu yang berarti komunikasi yang semakin luas dalam menpublikasikan setiap cerita dan artikel secara mandiri dan online. Logo ini didesain dan diberi warna ungu agar terkesan unik dan ceria. Dengan mengambil prinsip friendly, easy dan emotional elemen huruf e dilukiskan sebagai sebuah karakter dengan pembawaan yang fun dan much talking. Logo iMe mematahkan slogan "talk less do more” tetapi menjadi "more talk do more”. 


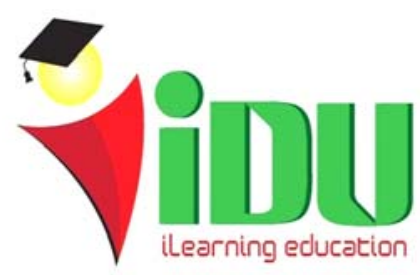

Gambar 8. Final Artwork Logo iDu

iDu merupakan sistem pembelajaran yang baru secara online yang ada di Perguruan Tinggi Raharja yang dapat diakses kapanpun dan dimanapun. Filosofi warna hijau pada logo mencerminkan sebuah pembaharuan yang menumbuhkan ide untuk menciptakan penelitian yang memudahkan mahasiswa dan civitas kampus dalam menjalankan segala kegiatan perkuliahan. Dengan bentuk Segitiga berwarna merah disisi kiri yang melambangkan bentuk kokoh, kekuatan dan sukses. Ini mengartikan dengan iDu setiap mahasiswa digiring menuju kesuksesan yang ditumbuhkan melalui sikap karakter dan kekuatan untuk belajar dan menampilkan inovasi-inovasi baru dalam teknologi pembelajaran guna kemajuan pendidikan masa depan.

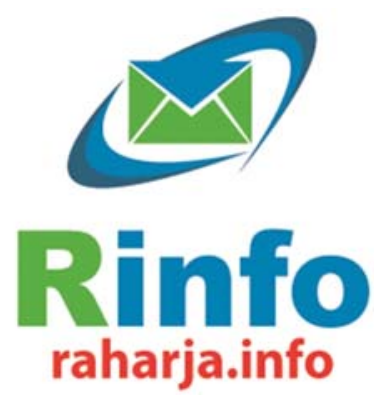

Gambar 9. Final Artwork Logo Rinfo

Rinfo merupakan prasarana komunikasi yang digunakan seluruh pribadi raharja. filosofi dari logo ini mengambil warna biru yang diartikan sebagai teknologi masa kini yang terintegrasi secara online sehingga memudahkan dalam berkomunikasi melalui elektronik mail dengan simbol panah melingkar yang artinya ruang lingkup dalam komunikasi Perguruan Tinggi Raharja. Sedangkan warna Hijau merupakan ciri khas dari Perguruan Tinggi Raharja dan juga mempunyai arti harapan dan pertumbuhan. yang disinggungkan bahwa email raharja.info diharapkan tumbuh menjadi media komunikasi primer di masa depan yang akan terus maju. 


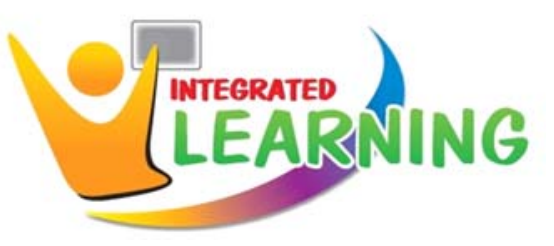

Gambar 10. Final Artwork Logo iLearning

iLearning merupakan metode sistem pembelajaran yang ada di Perguruan Tinggi Raharja. Bentuk lengkung yang ada dilogo tersebut dibuat warna warni menunjukkan unsur $4 \mathrm{~B}$ yaitu warna kuning melambangkan belajar, warna jingga melambangkan bermain, warna biru melambangkan bekerja dan warna ungu melambangkan berdoa. Simbol berbentuk orang menjelaskan bahwa ilearning sebuah pembelajaran yang menyenangkan dengan warna jingga yang berarti semangat untuk melakukan berbagai hal positif dalam pembelajaran. Logo didesain dalam kedinamisan dan memiliki kesan sebuah kegembiraan dalam proses belajar mengajar.

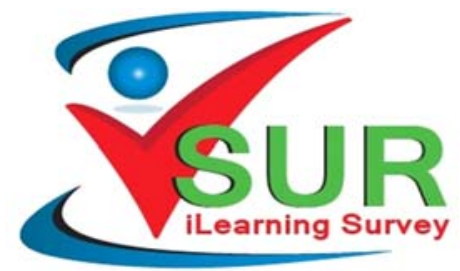

Gambar 11. Final Artwork Logo iSur

iSur merupakan sistem yang sudah terintergrasi secara online untuk melakukan suatu penilaian berbentuk survey. Filosofi dari logo ini mengambil simbol ceklist yang berarti sebagai alat untuk memperoleh hasil data yang diinginkan. Warna merah pada simbol berani memberikan hasil yang akurat dan cepat sesuai dengan pencapaian tujuan yang diinginkan. Arah lengkung elemen dari awal kecil menjadi membesar dimana pencapaian hasil dipusatkan pada satu titik hingga mendapatkan hasil data survey absolut.

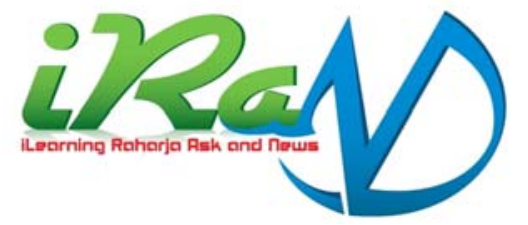

Gambar 12. Final Artwork Logo iRan 
iRan merupakan berita kampus yang sudah terkomputerisasi untuk mengelola semua dokumentasi tentang suatu peristiwa, kejadian serta informasi kampus. Bentuk N berbentuk lancip pada ujung-ujungnya diartikan menyajikan berita yang tajam, terpercaya dan bertanggung jawab. Lengkungan biru arah kedalam membawa efek mendunia, bahwa iRan dapat memberikan berita yang diakses secara update kapanpun dan dimanapun. Secara keseluruhan logo ini menggambarkan berita yang diberikan selalu update.

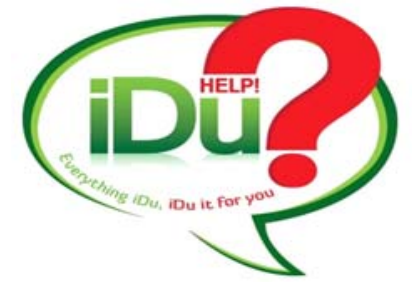

Gambar 13. Final Artwork Logo iDu Help!

iDUHELP! Merupakan sebuah fasilitas sistem online dan offline dengan pelayanan segala informasi yang dibutuhkan. Fasilitas ini dapat digunakan oleh pengguna untuk mempertanyakan berbagai macam informasi, dengan bertanya langsung kepada operator atau dengan email. Dengan simbolisasi tanda tanya berwarna merah itu melambangkan sistem ini menunjukkan integritas dalam pencapaian tujuan dengan hasil dapat menjawab pertanyaan yang memuaskan bagi penggunanya.

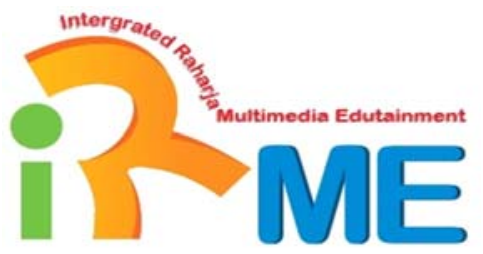

Gambar 14. Final Artwork Logo iRme

iRME merupakan media portofolio online yang terkomputerisasi bertujuan sebagai CV lifetime online. filosofi dari logo ini mengambil warna jingga pada huruf $\mathrm{R}$ yang diartikan sebagai sebuah semangat yang tinggi didalam mencapai sebuah tujuan yang disimbolkan huruf $\mathrm{R}$ seperti seseorang yang melangkah kedepan. Logo didesain dengan dinamis dan terkesan kreatif mencerminkan ternyata membuat CV tidaklah selalu monoton dan kaku. Keseluruhan logo ini menggambarkan seseorang yang siap melangkah kedepan dengan optimis. 


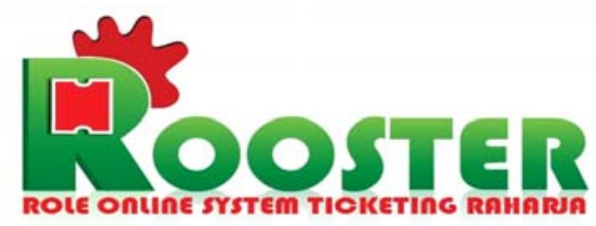

Gambar 15. Final Artwork Logo Rooster

Rooster merupakan pelayanan informasi online menggunakan sebuah ticket. Filosofi dari logo ini mengambil warna merah dari jambul ayam yang diartikan sebagai semangat seperti ayam yang selalu ontime bangun paling pagi untuk memberikan pelayanan yang terbaik dan berkualitas yang disimbolkan cepat tanggap dalam melayani segala permintaan costumer.

\section{KESIMPULAN}

Berdasarkan dari hasil Perancangan Identitas Logo sebagai Penunjang Program-program Di Divisi Raharja Enrichment Centre pada Perguruan Tinggi Raharja, maka dapat disimpulkan bahwa untuk menciptakan Identitas Logo yang menarik maka diperlukan study kasus, ide, data, proses desain yang menggunakan harmonis yang dapat menyampaikan image atau citra dari Perguruan Tinggi Raharja sebagai kampus IT serta ilustrasi gambar yang unik, layout, penggunaan tipografi yang tepat serta Identitas Logo dapat di implementasikan sebagai identitas visual dalam menampilkan program-program Raharja Enrichment Centre (REC) maka rancangan yang dibuat sesuai dengan karakter program-program yang ada seperti menggunakan ilustrasi simbol atau type font yang sesuai dengan program Raharja Enrichment Centre (REC).

\section{DAFTAR PUSTAKA}

1. Adrian, Rully. 2013. Perancangan Media Komunikasi Visual Sebagai Sarana Penunjang Promosi Pada Sma Daan Mogot Tangerang.

2. Binanto, Iwan. 2010. Multimedia Digital (Dasar Teori dan Pengembangannya). Yogyakarta : ANDI Offset.

3. Caniago, Ferri. 2012. Cara Mutakhir Jago Desain Logo. Jakarta Timur : Niaga Swadaya. 
4. Febrina, Chyki dan Eka Rizkiantono, R. 2013. Jurnal Sains dan Seni Pomits Vol. 2, No. 1 : Perancangan Identitas Visual Kampoeng Sepatu Sandal Krian sebagai Kampoeng Wisata Industri di Sidoarjo. Institut Teknologi Sepuluh Nopember (ITS). Surabaya.

5. Harisah, Afifah dan Masiming, Zulfitria. 2008. Jurnal Smartek Vol. 6 No. 1 : Persepsi Manusia Terhadap Tanda, Simbol dan Spasial.

6. Hendratman, Hendi. 2010. Tips N Trik Computer Graphics Design. Bandung : Informatika Bandung.

7. Hidayati. 2011. Theory and Application of IT Research: Metodologi Penelitian Teknologi Informasi. Yogyakarta: Andi Offset.

8. Jogiyanto. 2012. Yakub (Pengertian Sistem Informasi). Yogyakarta : Graha Ilmu.

9. Kuwayama, Yasaburo. 2009. Mendesain Logo. Jakarta : PT. Gramedia.

10. McLeod. 2012. Yakub (Pengantar Sistem Informasi). Yogyakarta : Graha llmu

11. Mulyanto, Agus. 2009. Sistem Informasi Konsep dan Aplikasi. Yogyakarta : Pustaka Pelajar.

12. O’Brien. 2012. Yakub (Pengantar Sistem Informasi). Yogyakarta : Graha Ilmu.

13. Primandono , Dityo Wahyu. 2010. Jurnal Desain Idea : Perancangan Corporate Identity PT. Yasa Industri Nusantara Yang Mampu Merepresentasikan Visi dan Misi, Filosofi Perusahaan dan Servis Bisnis Yang Berupa EPC. Surabaya. Kampus ITS Sukolilo.

14. Rustan, Surianto. 2009. Mendesain Logo. Jakarta : PT. Gramedia.

15. Supriyono, Rakhmat. 2010. Desain Komunikasi Visual Teori dan Aplikasi. Yogyakarta: Andi Offset.

16. Tjiptono, Fandy. 2008. Strategi Pemasaran. Yogyakarta, Andi Offset.

17. Wardani, Riatma Suci. 2011. Redesign Corporate Identity DanPerancangan Graphic Standar Manual Pada Pt. Dunia Bangunan.

18. Widada, Sugeng Drs. 2010. ”Diktat Mata Kuliah Nirmana”. Tangerang : Perguruan Tinggi Raharja. 